\title{
Parallels among positive-strand RNA viruses, reverse-transcribing viruses and double-stranded RNA viruses
}

\section{Paul Ahlquist}

Abstract | Viruses are divided into seven classes on the basis of differing strategies for storing and replicating their genomes through RNA and/or DNA intermediates. Despite major differences among these classes, recent results reveal that the non-virion, intracellular RNAreplication complexes of some positive-strand RNA viruses share parallels with the structure, assembly and function of the replicative cores of extracellular virions of reverse-transcribing viruses and double-stranded RNA viruses. Therefore, at least four of seven principal virus classes share several underlying features in genome replication and might have emerged from common ancestors. This has implications for virus function, evolution and control.

Positive-strand RNA virus A virus, the infectious virions of which contain the genome in a single-stranded, messengersense RNA form.
Institute for Molecular Virology and Howard Hughes Medical Institute, University of Wisconsin-Madison, Madison, Wisconsin 53706, USA.

e-mail:ahlquist@wisc.edu doi:10.1038/nrmicro1389 Published online 3 April 2006
Despite continuing advances, established and emerging viruses remain major causes of human disease, with dramatic costs in mortality, morbidity and economic terms. In addition to acute diseases, viruses cause at least $15-20 \%$ of human cancers ${ }^{1,2}$ and are implicated in neurological and other chronic disorders. One of many challenges in controlling viruses and virus-mediated diseases is that viruses show an amazing diversity in basic characteristics and life cycles, including differences in virion structure, replication strategies, genetic organization, gene expression and many other fundamental processes. Therefore, even the very processes against which antivirals are targeted often differ radically among virus classes. Inherent in this remarkable variety are intriguing issues about the multiplicity of virus origins and the functional and evolutionary relations of existing viruses. Such issues have practical as well as academic importance, as underlying similarities among virus classes might serve as a foundation for broader-spectrum antiviral strategies.

One of the most elemental differences among viruses is their diversity in genome replication and encapsidation strategies, which define seven major classes (FIG. 1). Some viruses replicate their genomes solely through DNA intermediates, packaging these genomes in infectious virions either as double-stranded (ds)DNA or single-stranded (ss)DNA. By contrast, most viruses replicate their genomes solely through RNA intermediates. Such RNA viruses are divided into three classes based on whether their virions package the genome as mRNA-sense (positive-strand) ssRNA, antisense (negative-strand)
ssRNA or dsRNA. Other viruses replicate by interconverting their genomes between RNA and DNA. The virions of such reverse-transcribing viruses always initially package the RNA forms of their genomes, and either might (for example, hepadnaviruses and foamy retroviruses) or might not (for example, orthoretroviruses) reverse-transcribe the RNA into DNA before the virion exits the initially infected producer cell.

Viruses in each of these seven classes tend to share additional features, such as gene-expression strategies and so on, that further cluster and differentiate their members from the other classes, showing that these classes represent meaningful, functionally distinct groupings and probable evolutionary lineages. Some of these variations arise because the type of nucleic acid delivered by the virion to a target cell dictates early infection and gene-expression steps. For example, to initiate viral gene expression, dsRNA virus virions and negative-strand RNA ((-)RNA) virus virions contain viral polymerases that transcribe the genome into translatable mRNA, and reverse-transcribing-virus virions contain polymerases that copy the genome into cell-transcribable DNA (BOX 1). Positive-strand RNA ( + ) RNA) viruses, the virions of which deliver immediately translatable messenger-sense RNAs, encapsidate their RNA without a polymerase and form strictly intracellular RNA-replication and mRNAtranscription complexes (BOX 1).

Despite these and other differences, recent results have revealed fundamental parallels in the genomereplication processes of certain (+)RNA viruses, dsRNA viruses and reverse-transcribing viruses. In particular, the 


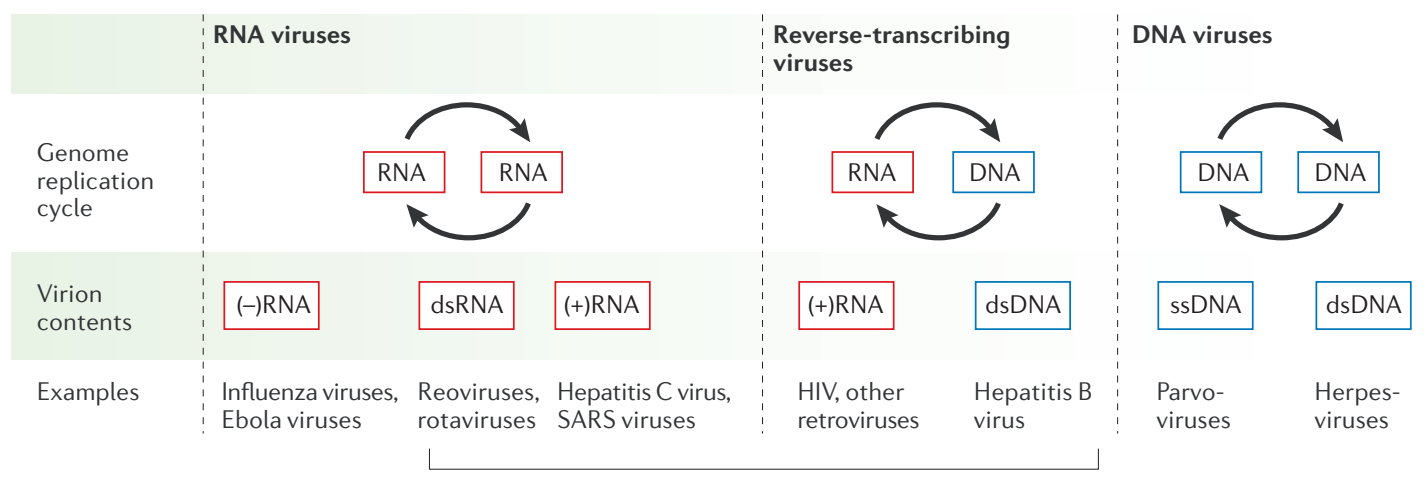

Figure 1 Seven classes of virus distinguished by genome replication and encapsidation strategies. The bracket highlights the four virus classes emphasized in this review. (+)RNA, positive-strand RNA, which is single-stranded RNA of the same polarity as viral mRNA; (-)RNA, negative-strand RNA, which is single-stranded RNA of anti-mRNA polarity; dsRNA, double-stranded RNA; SARS, severe acute respiratory syndrome.

intracellular RNA-replication complexes of some, if not many, $(+)$ RNA viruses share several similarities with the replicative cores of virions from both dsRNA viruses and reverse-transcribing viruses. This review outlines these similarities and their potential implications for virus function and evolution. As primary examples, we review similarities among $(+)$ RNA viruses in the alphavirus-like superfamily, the dsRNA reoviruses and the retroviruses. Other shared characteristics with similar evolutionary implications have been recognized recently among certain other (+)RNA viruses, the dsRNA birnaviruses and the reverse-transcribing hepadnaviruses, including parallels in viral RNA-polymerase structure, capsid proteins and protein priming of genome replication ${ }^{3-7}$.

Negative-strand RNA ((-)RNA) viruses (FIG. 1) also share similarities with some of the basic features reviewed here, suggesting that the functional and evolutionary parallels discussed below might be extended further. These possibilities are not discussed here in detail for reasons of space. In addition, whereas (+)RNA viruses, dsRNA viruses and reverse-transcribing viruses each use identical (+)RNA molecules as genome-replication intermediates and mRNAs, (-)RNA viruses are distinguished by using different forms of $(+)$ RNA for these functions.

\section{(+)RNA virus and retrovirus parallels}

$t R N A s$ and genome replication. One of the first similarities recognized between the replication of retroviruses and (+)RNA viruses was the role of tRNAs in initiating retroviral reverse transcription and of tRNA-like elements in initiating RNA replication by a subset of $(+)$ RNA viruses such as the bromoviruses ${ }^{8,9}$ (FIG. 2). Bromoviruses, discussed further below, have three genomic RNAs with highly conserved, structured, tRNA-like $3^{\prime}$ ends (FIG. 2b). These $3^{\prime}$ ends terminate in $3^{\prime}-\mathrm{CCA}_{\mathrm{OH}}$ sequences that are completed by tRNA-nucleotidyl transferase, they are specifically aminoacylated in vitro and in vivo with tyrosine, and they contain the promoter for (-)RNA synthesis ${ }^{10-13}$.

tRNA-related sequences initiate negative-strand synthesis for genomic RNA replication in both retroviruses and (+)RNA viruses, but the mechanisms are distinct. For retroviruses, a cellular tRNA covalently primes negativestrand cDNA synthesis, whereas for the relevant (+)RNA viruses, a viral tRNA-like element serves as a recognition site and template for (-)RNA synthesis that is initiated de novo, without a primer. A natural intermediate and potential evolutionary link between these processes was identified by Lambowitz and colleagues, who showed that a Neurospora crassa mitochondrial retroplasmid initiates reverse transcription without a primer at the tRNA-like $3^{\prime}$ end of its genomic RNA, paralleling negative-strand initiation by $(+)$ RNA viruses ${ }^{14}$.

Membrane-associated RNA-replication complexes. As noted above, $(+)$ RNA viruses differ from retroviruses and other RNA viruses in that they do not encapsidate their polymerases in extracellular virions. Nevertheless, emerging results show that similarities between (+)RNAvirus RNA replication and retrovirus reverse transcription are not limited to aspects of negative-strand initiation and the general similarities of RNA and DNA polymerases. Instead, as detailed below, (+)RNA-virus RNA replication occurs in virus-induced compartments which have many similarities to the replicative cores or capsids of retrovirus virions.

$(+)$ RNA-virus replication is invariably localized to intracellular membranes. Different (+)RNA viruses target distinct but usually specific membranes, such as those of the endoplasmic reticulum (ER) ${ }^{15-19}$, endosomes ${ }^{20,21}$, mitochondria $^{22}$ or chloroplasts ${ }^{23}$. RNA replication is usually associated with rearrangements of these target membranes, often giving rise to membrane invaginations, single- or double-membrane vesicles, membranebound vesicle packets and other structures.

For many (+)RNA viruses, RNA synthesis localizes to membranes bearing 50-70-nm vesicular compartments that are invaginated away from the cytoplasm into the lumen of the affected secretory compartment or organelle. Such invaginations, termed spherules, were first visualized in early electron microscopy (EM) studies of alphavirus-infected cells ${ }^{20,21}$. There are many other examples of such invaginations in and beyond the alphavirus-like superfamily, such as those associated with bromoviruses ${ }^{24,25}$, nodaviruses ${ }^{22}$ and tymoviruses ${ }^{23}$. 


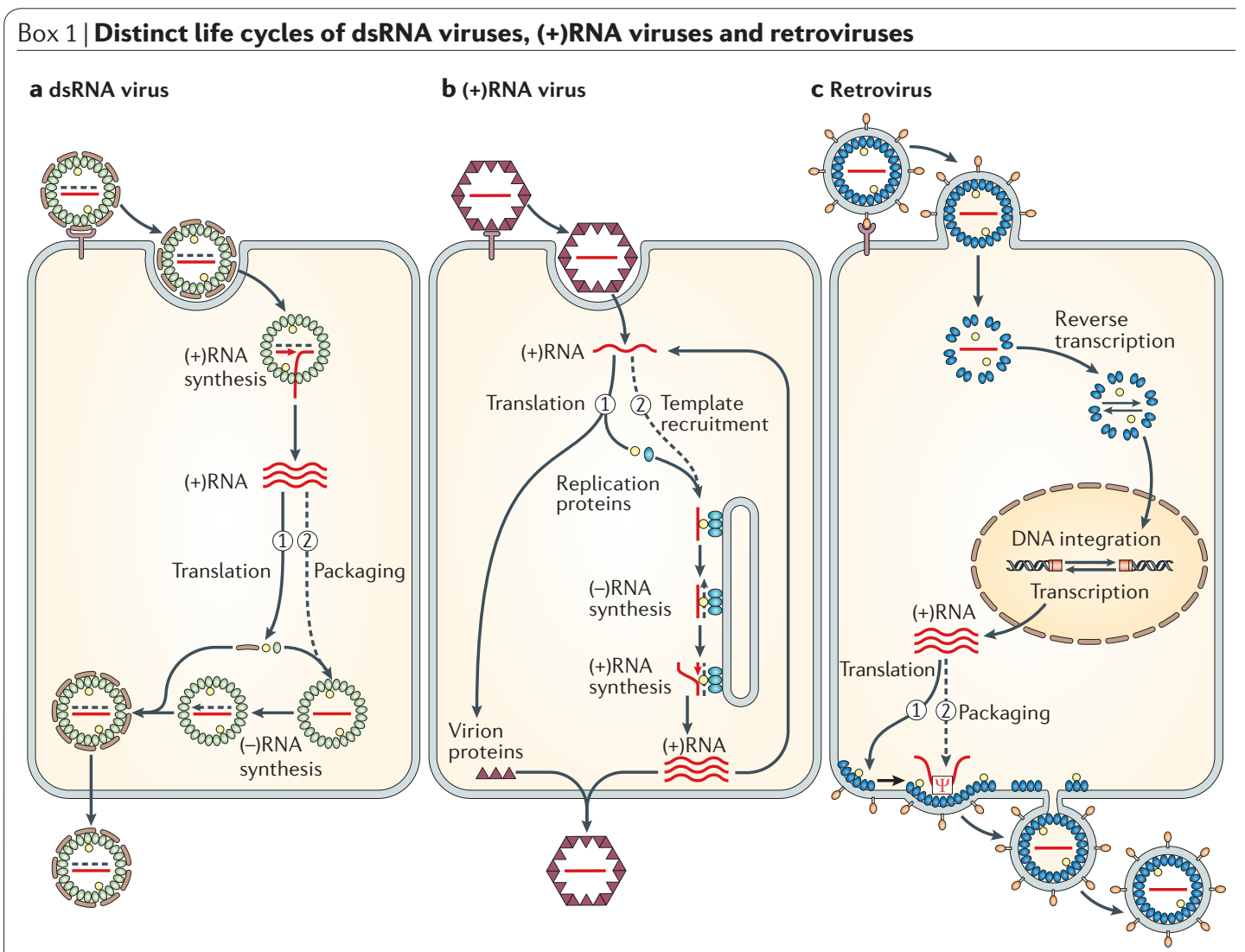

All three classes of virus replicate through positive-strand RNA ((+)RNA) intermediates (red strands in the figure) that are templates for both translation and genome replication. For each class, the figure shows a simplified, representative life cycle.

\section{Double-stranded (ds)RNA viruses}

As shown in part a of the figure, virus attachment and endocytosis deliver a virion core that contains viral genomic dsRNA and viral RNA polymerase (yellow) into the cytoplasm. The core transcribes and extrudes (+)mRNAs that are first translated (1) and then packaged (2) by the resulting viral proteins into new virion cores. Cores mature by synthesizing negativestrand (-)RNA (dotted strand) and adding exterior proteins. They exit by cell lysis or secretion.

\section{(+)RNA viruses}

As shown in part $\mathbf{b}$ of the figure, endocytosed virions release messenger-sense genomic RNA into the cytoplasm for translation. Newly translated viral RNA-replication proteins recruit this genomic RNA into a membrane-associated, intracellular RNA-replication complex. Small amounts of (-)RNA are produced and used as templates to greatly amplify viral (+)RNA, which is encapsidated into new progeny virions.

Retroviruses

As shown in part $\mathbf{c}$ of the figure, virion attachment and envelope fusion release a subviral complex that contains viral genomic (+)RNA and reverse transcriptase (yellow). After cDNA synthesis by reverse transcription, proviral cDNA is integrated into the host chromosome and transcribed to produce (+)RNA that is translated (1) and then packaged (2) into new virions that are released by budding.

As illustrated in FIG. 3a-c, for nodaviruses and bromoviruses, such spherules frequently occur in contiguous clusters and are often light-bulb-shaped structures, the interiors of which are connected to the cytoplasm through membranous necks.

Parallels with retrovirus capsids. Retroviruses package their reverse transcriptase (also designated Pol) and their genomic RNA templates into membrane-enveloped capsid shells assembled by the major capsid protein, $\mathrm{Gag}^{26-28}$ (FIG. 4a). For most retroviruses, these capsids bud from the cell together with viral envelope proteins and are delivered to new cells by infection, giving rise to intracellular complexes in which reverse transcription occurs $^{29-31}$. For foamy retroviruses and retrovirus-like LTR (long terminal repeat) retrotransposons, reverse transcription occurs in such capsids without leaving the producer cell ${ }^{32-34}$. Such capsids contain hundreds ${ }^{35}$ to thousands ${ }^{36}$ of Gag proteins and approximately 10-20-fold fewer Gag-Pol fusion protein ${ }^{28,37}$. Retrovirus genomic RNAs are selectively packaged in these capsids by Gag interaction with specific cis-acting signals, often designated as $\Psi^{38,39}$.

Recently, links between the intracellular spherules of $(+)$ RNA viruses and retrovirus capsids emerged from studies of brome mosaic virus (BMV) RNA replication. 

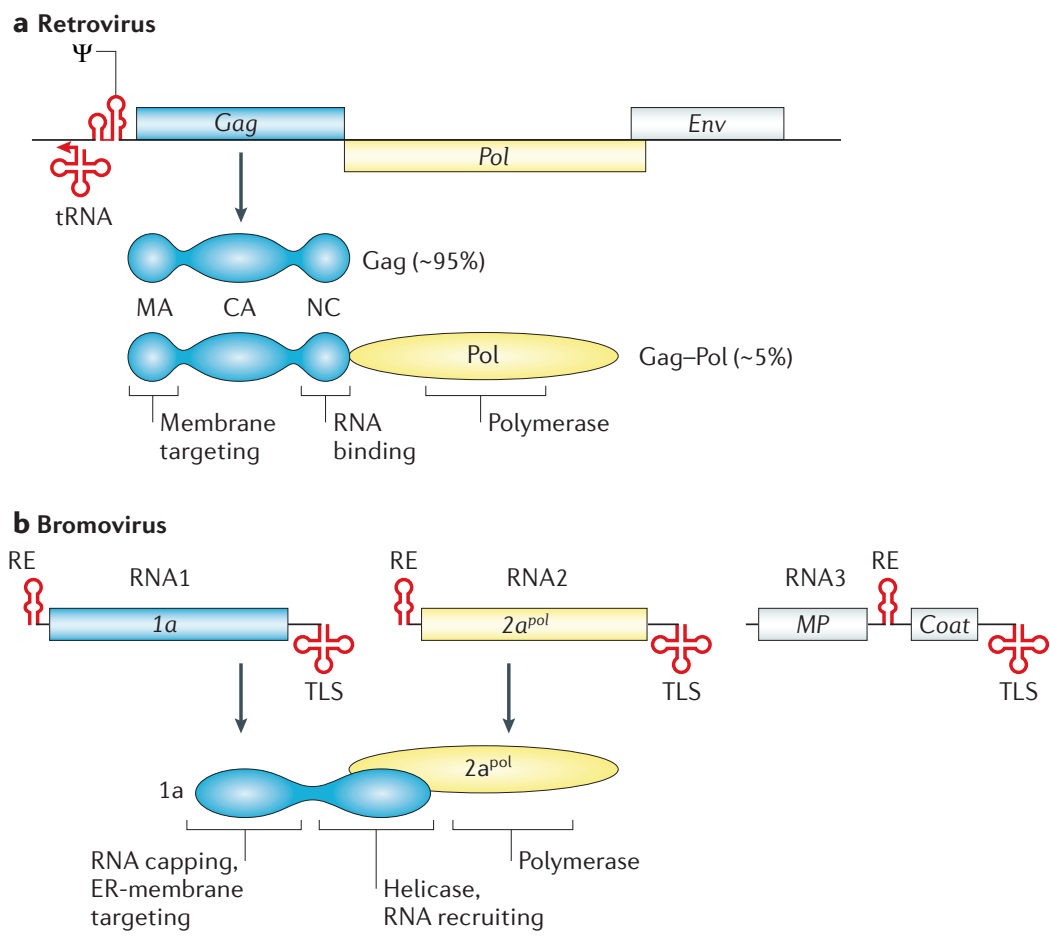

Figure 2 | Schematic overview of retrovirus and bromovirus genomes. a| Schematic of the genomic RNA of a simple retrovirus and encoded virion proteins Gag and Gag-Pol. b | Schematic of bromovirus genomic RNAs 1, 2 and 3 and encoded RNA-replication factors $1 \mathrm{a}$ and $2 \mathrm{a}^{\mathrm{pol}}$. CA, capsid; Env, envelope-protein gene; ER, endoplasmic reticulum; $\mathrm{MA}$, matrix; NC, nucleocapsid; RE, RNA template recruiting element for genomic RNA replication; TLS, 3' tRNA-like sequence, which contains the promoter for negative-strand RNA synthesis; tRNA, host tRNA primer for negative-strand cDNA synthesis; $\Psi$, RNApackaging signal.

BrUTP labelling

Labelling RNA by replacing the substrate UTP with 5-bromo-

UTP (BrUTP). The labelled RNA can be localized using electron microscopy following immunogold labelling with an antibody directed against BrU.
BMV is the type member of the bromoviruses and a representative member of the alphavirus-like superfamily of (+)RNA viruses. This superfamily includes many viruses that infect animals or plants, all of which share three conserved protein domains that are involved in RNA replication $^{40,41}$. In BMV, these domains are distributed across two replication proteins, $1 \mathrm{a}$ and $2 \mathrm{a}^{\mathrm{pol}}$ (FIG. 2b), that co-localize on ER membranes at the sites of viral RNA synthesis ${ }^{15,16}$. 1a contains an RNA-helicase-like domain and an RNAcapping domain with $\mathrm{m}^{7} \mathrm{G}$ methyltransferase and covalent $\mathrm{m}^{7} \mathrm{G}$ binding activities required for capping of viral RNAs in $v i v o^{42-44} .2 \mathrm{a}^{\mathrm{pol}}$ contains a central polymerase domain.

Protein 1a is a multifunctional protein with central roles in the genesis and operation of BMV RNAreplication complexes (FIG. 4b). In the absence of other viral factors, 1a localizes to ER membranes ${ }^{16}$ and induces invagination of the spherular replication compartments ${ }^{45}$. 1a also recruits nascent or full-length $2 \mathrm{a}^{\mathrm{pol}}$ to ER membranes by an interaction between the 1a helicaselike domain and the $\mathrm{N}$-terminal extension that precedes the $2 \mathrm{a}^{\mathrm{pol}}$ polymerase domain ${ }^{46-48}$.

Protein 1a also transfers BMV genomic RNAreplication templates to a new state, which was first recognized because the stability and accumulation of BMV genomic RNAs was dramatically increased by $1 \mathrm{a}$ co-expression in yeast ${ }^{49-51}$. Subsequent work showed that $1 \mathrm{a}$ induces the transfer of BMV genomic RNAs to a novel, membrane-associated, nuclease-resistant state ${ }^{45}$. The location of the nuclease-resistant RNA and the site of RNA synthesis seem to be the spherule interior, as (+)RNA and (-)RNA templates and nascent BMV RNAs show identical membrane association and nuclease resistance, and immunogold EM localizes 5-bromo-UTP (BrUTP)-labelled nascent RNAs to the spherule interior ${ }^{45}$.

Recruitment of BMV genomic RNAs to the RNAreplication complex by 1a is controlled in cis by internal (RNA3) or 5' proximal (RNA1 and RNA2) recruitment elements (REs) on each genomic RNA (FIG. 2b), which are necessary and sufficient for 1a responsiveness ${ }^{51,52}$. Mutational studies show that the RE activity of BMV RNA derivatives in 1a-induced recruitment is closely linked to their relative template activity in (-)RNA synthesis and full RNA replication ${ }^{51,52}$. Therefore, 1a-responsive RNA-template recruitment seems to be a crucial step that precedes replication.

As shown in FIG. $4 a, b$, the roles of $1 \mathrm{a}, 2 \mathrm{a}^{\mathrm{pol}}$ and the cis-acting REs parallel the roles of Gag, Pol and $\Psi$ in retrovirus replication. Similar to Gag, 1a localizes to the cytoplasmic face of membranes as a peripheral membrane protein ${ }^{53}$, self-interacts ${ }^{54}$, and is the sole viral factor required to induce membrane invagination ${ }^{45}$. Immunogold EM labelling and biochemical analyses show that each spherule contains hundreds of 1 a proteins ${ }^{45}$. The resulting spherules (FIG. 3c) are remarkably similar to the necked vesicles that result when retrovirus budding is arrested by mutations in the Gag late domain that recruits host factors required for membrane breakage and fusion ${ }^{55}$. Moreover, the high multiplicity of $1 \mathrm{a}$ in spherules, its strong membrane association and self-interaction, and the dependence of endocytic and secretory vesicle formation and enveloped-virion budding on protein coats or shells ${ }^{56,57}$ indicate that 1a might induce membrane invagination by forming a capsid-like shell similar to that of Gag. Similarly, the 1a-RE interaction in RNA-template recruitment parallels the Gag- $\Psi$ interaction in retrovirus RNA packaging. Like retrovirus Pol, BMV $2 \mathrm{a}^{\mathrm{pol}}$ is not required for spherule formation or RNA recruitment. However, when expressed, $2 \mathrm{a}^{\mathrm{pol}}$ is incorporated into the replication complex in a $1 \mathrm{a} / 2 \mathrm{a}^{\mathrm{pol}}$ ratio of $\sim 25$, similar to the Gag/Pol ratio of 10/20 (REFS 37,45).

\section{Similarities with other (+)RNA viruses}

The universal association of (+)RNA-virus RNA replication with modified intracellular membranes, often in association with membrane invaginations, and other shared features imply that the RNA-replication complexes of a wide variety of $(+)$ RNA viruses might use principles that are similar to those illustrated in FIG. 4b. Such parallels include the following: both alphavirus- and cucumovirus-induced membrane spherules contain dsRNA ${ }^{25,58}$; BrUTP labelling implies that the interiors of alphavirus spherules are the sites of viral RNA synthesis ${ }^{59}$; hepatitis C virus and coronavirus (-)RNA-replication templates are in a membrane-associated, nuclease-resistant state $e^{60-62}$; hepatitis $\mathrm{C}$ virus replication proteins are present in active replication complexes at $>100$-fold excess over viral RNA and are sequestered in a protease-resistant 
state $^{61,62}$; poliovirus polymerase and possibly other replication factors self-oligomerize in extended lattices ${ }^{63}$; and tombusvirus genomic RNA possesses an internal cis signal for initial template recruitment and separate $3^{\prime}$ terminal sequences for negative-strand initiation ${ }^{64}$.

Furthermore, just as for retrovirus Gag and BMV 1a, the membrane structures associated with genome replication by many $(+)$ RNA viruses can be induced by a subset of viral RNA-replication proteins that do not include the polymerase. Examples include the RNAreplication-associated membrane structures induced by alphavirus nsP123 (REF. 65), arterivirus nsp2 and nsp3 (REF. 66), hepatitis C virus nsP4B (REFS 19,67) and picornavirus 2BC (REFS 18,68,69).

As explained further below, the parallels among (+)RNA-virus RNA-replication complexes, retrovirus capsids and dsRNA-virus capsids (FIG. 4) imply possible mechanistic explanations for several common features of (+)RNA-virus RNA replication, such as the ability of the replication complex to retain (-)RNA templates for positive-strand synthesis, differential regulation of $(-)$ RNA and (+)RNA synthesis, and frequent downregulation of polymerase expression.

Pol regulation in retroviruses and (+)RNA viruses. In retrovirus genomes, the Pol open reading frame (ORF) follows that of Gag and is expressed by a rare translational frameshift or translational readthrough event, generating an $\sim 20$-fold ratio of Gag/Gag-Pol (FIG. 2a) that is incorporated into the final virion (FIG. 4a). This highly asymmetric ratio regulates the free volume and other parameters of the capsid, and is functionally important, as increasing the level of Gag-Pol relative to Gag inhibits retrovirus virion assembly, release and infectivity ${ }^{37,70,71}$.

Similarly, many (+)RNA viruses downregulate expression of their polymerase relative to RNA-replication proteins related in sequence and/or functions to $1 \mathrm{a}$. The finding that BMV 1a parallels Gag in acting at high multiplicity to induce the RNA-replication compartment (FIG. 4a,b) implies that such polymerase downregulation might satisfy functional requirements similar to those governing the Gag/Gag-Pol ratio in retrovirus capsids. Like retroviruses, many (+)RNA viruses use translational readthrough or frameshift to downregulate polymerase expression. Well-studied examples include the animal alphaviruses and arteriviruses and plant tobamoviruses and tombusviruses. In each case, the ORF upstream to that of polymerase encodes a protein(s) with parallels to 1a. Specifically, alphavirus nsP123 and tobamovirus p130 are homologous to $1 \mathrm{a}$ (REF. 40), and nsP123 is sufficient to induce membrane spherules $^{65}$; arterivirus ORF1a proteins induce membrane rearrangements associated with RNA replication $^{66}$; and tombusvirus p33 self-interacts and directs membrane association of itself, viral RNA and polymerase $^{72}$. As with Gag and Pol, increasing expression of the polymerase-containing fusion proteins at the expense of the upstream membrane-interacting proteins inhibits tobamovirus and alphavirus replication ${ }^{73,74}$.

Unlike the above examples, bromoviruses express 1a and $2 \mathrm{a}^{\mathrm{pol}}$ from separate genomic RNAs (FIG. 2b). In this

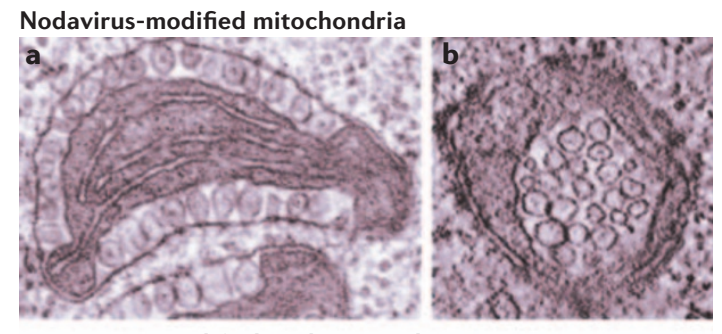

Bromovirus-modified nuclear membranes

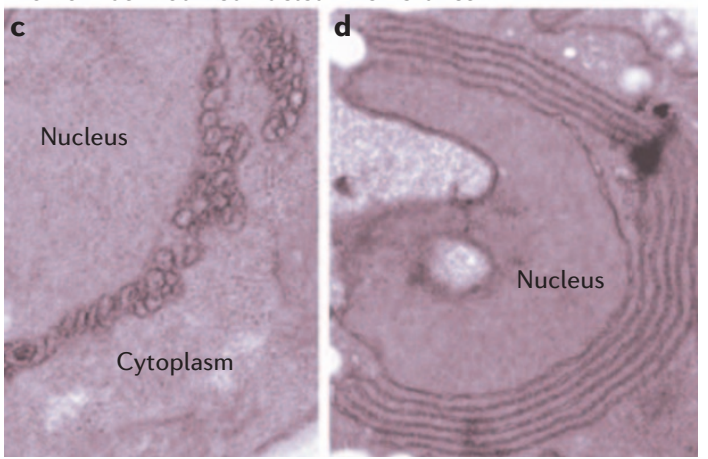

Figure 3 | Electron micrographs of membrane rearrangements associated with nodavirus and bromovirus RNA replication. a | Mitochondria in a flockhouse-nodavirus-infected Drosophila cell, showing the typical 50-70-nm, light-bulb-shaped spherular invaginations of the outer mitochondrial membrane into the expanded lumen between the inner and outer membranes. Reproduced with permission from REF. 22 (c) (2001) American Society for Microbiology.

b | Mitochondrion in a flock-house-nodavirus-infected Drosophila cell that has been sectioned perpendicular to the axis of the spherule necks, rather than parallel to these axes as in panel a. This view reveals a 'vesicle packet' appearance (B. Kopek and P.A., unpublished results). Note that invagination into the lumen of any closed membrane compartment such as the endoplasmic reticulum (ER) or mitochondrial envelope creates a spherule interior that remains connected to the cytoplasm, but that in the section shown in $\mathbf{b}$, the spherule appears separated from the cytoplasm by two or more bounding membranes. c| Similar 50-70-nm spherular vesicles invaginated from the outer perinuclear ER membrane into the ER lumen, in a yeast cell expressing brome mosaic virus (BMV) replication factor 1a in the absence of other viral components. Indistinguishable spherules occur in cells expressing $1 \mathrm{a}$ and $\mathrm{BMV} 2 \mathrm{a}^{\mathrm{pol}}$ in a 20/1 ratio and replicating BMV RNA3. Reproduced with permission from REF. 45 (C) (2002) Elsevier. d | Karmellaelike layering of the outer perinuclear ER membrane in cells expressing BMV 1a plus elevated levels of BMV $2 \mathrm{a}^{\mathrm{pol}}$, and replicating BMV RNA3. Note at top and bottom left that the $\sim 60$-nm intermembrane space is contiguous with the cytoplasm. Reproduced with permission from REF. 84 (C) (2004) National Academy of Sciences, USA.

regard, they parallel the foamy virus genus of retroviruses, which express Gag and Pol as independent proteins from separate mRNAs ${ }^{34}$. Although expressed separately, direct in vivo interaction between the C-terminal 1a helicase domain and $\mathrm{N}$-terminal sequences of nascent $2 \mathrm{a}^{\mathrm{pol}}$ results in a $1 \mathrm{a}-2 \mathrm{a}^{\mathrm{pol}}$ complex with a polarity that is reminiscent 
of orthoretrovirus Gag-Pol ${ }^{46-48}$ (FIG. 2). Moreover, whereas translation from separate $\mathrm{mRNAs}$ precludes regulation by frameshift or readthrough, BMV downregulates $2 \mathrm{a}^{\mathrm{pol}}$ at translation initiation ${ }^{75}$ and by degradation of $2 \mathrm{a}^{\mathrm{pol}}$ that is not complexed with $1 \mathrm{a}$ (REF. 76). $1 \mathrm{a}-2 \mathrm{a}^{\mathrm{pol}}$ interaction itself is downregulated by competing $1 \mathrm{a}-1 \mathrm{a}$ interaction ${ }^{54}$ and $2 \mathrm{a}^{\mathrm{pol}}$ phosphorylation $^{77}$. Therefore, like alphaviruses ${ }^{78}$, bromoviruses have evolved several mechanisms to reduce polymerase accumulation and incorporation to achieve the retrovirus-like 1 a to $2 \mathrm{a}^{\mathrm{pol}}$ ratio of $25 / 1$ in RNA-replication complexes ${ }^{45}$.

Some other (+)RNA viruses, such as hepatitis C virus and picornaviruses, use polyprotein expression strategies that translate all viral ORFs, including polymerase, at equimolar levels. In at least some of these cases, only a fraction of polymerase sequences might be active owing to production of processing intermediates that lack polymerase sequences or activity, polymerase-active and -inactive conformers, polymerase sequestration in the nucleus and/or inclusion bodies, and other effects ${ }^{62,79}$. Some retrotransposons that produce equimolar levels of Gag and Pol appear to use related strategies to regulate polymerase incorporation or activity ${ }^{80,81}$.
Alternative membrane rearrangements. Whereas RNA replication by many (+)RNA viruses induces spherular membrane invaginations similar to those shown in FIG. 3a-c, some (+)RNA viruses induce alternative membrane rearrangements. In many cases, the topologies of these rearranged membranes remain under investigation and, as discussed below, some superficially distinct membrane structures might share underlying parallels in topology, assembly and function. Similarly, depending on the conditions, retrovirus Gag not only assembles normal capsids but also sheets, tubes and other structures ${ }^{82}$.

Flavivirus RNA replication localizes to packets in which an outer bounding membrane surrounds 50-100-nm vesicles that label with antibodies to viral RNA-replication proteins and dsRNA ${ }^{83}$. These vesicle packets are similar to EM views of BMV spherules invaginated into the ER lumen ${ }^{84}$ or nodavirus spherules invaginated into the lumen between the inner and outer mitochondrial membranes ${ }^{22}$, when sectioned perpendicular to the direction of invagination (FIG. 3b). BrUTP-labelled RNA synthesis by the related hepatitis C virus localizes to potentially similar clusters of $\sim 85-\mathrm{nm}$ vesicles surrounded by undulating membranes, termed

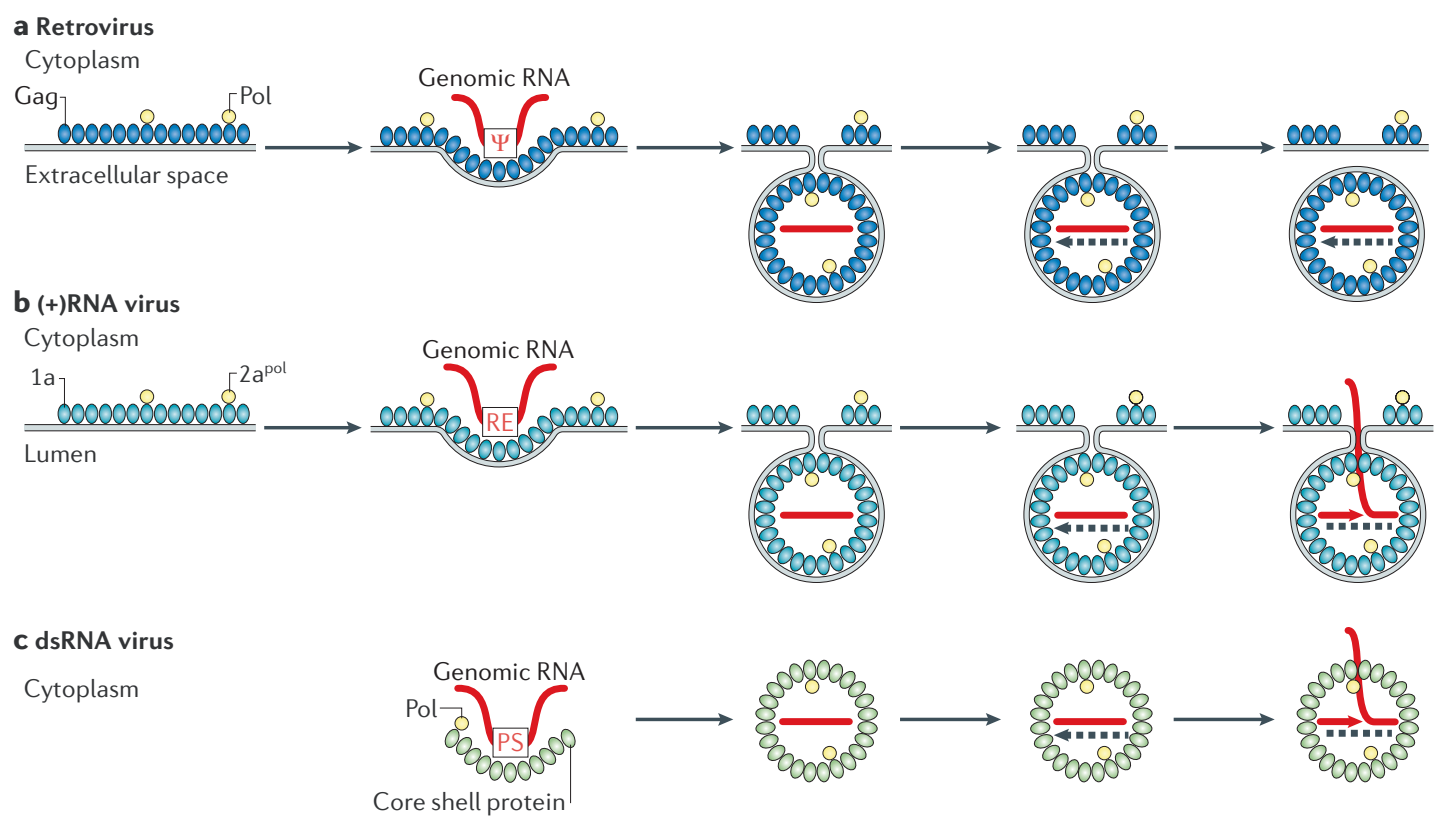

Figure 4 | Parallels between structure, assembly and function of retrovirus capsids, dsRNA-virus capsids and (+)RNA-virus RNA-replication complexes. Highly simplified schematics are shown in each case. a |Assembly of a retrovirus capsid includes the interaction of membrane-associated Gag and Gag-Pol. Gag-dependent genomic RNA encapsidation takes place through packaging signal $\Psi$, and this is followed by budding. To emphasize similarities with panels $\mathbf{b}$ and $\mathbf{c}$, synthesis of negative-strand cDNA (dashed lines) is shown prior to budding, as occurs for foamy retroviruses. $\mathbf{b} \mid$ Assembly and function of a bromovirus RNA-replication complex at the outer endoplasmic-reticulum membrane includes interaction of membrane-associated $1 \mathrm{a}$ and $2 \mathrm{a}^{\mathrm{pol}}$. 1a-dependent genomic RNA encapsidation takes place through the recruitment element (RE) template recruitment signal. This is followed by synthesis and retention of negative-strand RNA (dashed black lines), and asymmetric synthesis and export of positive-strand progeny RNA (red lines), which for at least some positive-strand RNA ((+)RNA) viruses proceeds by a semi-conservative mechanism as shown ${ }^{143}$. c|Assembly and function of the capsid core of a generalized double-stranded (ds)RNA virus includes encapsidation of genomic RNAs by a packaging signal (PS), synthesis and retention of negative-strand RNA (dashed black lines) and subsequent asymmetric synthesis and export of positive-strand progeny RNA (red lines). (+)RNA synthesis by dsRNA viruses can be either semi-conservative ${ }^{144}$, as shown, or conservative ${ }^{90,145}$. 
the membranous web ${ }^{19,67}$. Recently, models with strong parallels to bromovirus replication complexes have been proposed for RNA-replication complexes of hepatitis $\mathrm{C}$ virus ${ }^{62,85}$.

RNA replication by picornaviruses, arteriviruses and coronaviruses occurs in conjunction with doublemembrane vesicles, that is, vesicles bearing two closely appressed bounding membranes ${ }^{17,18,86}$. Similar to spherules, arterivirus double-membrane vesicles are thought to form by invagination of appressed ER membranes ${ }^{17}$. Some EM sections of poliovirus double-membrane vesicles display a narrow neck that connects the inner and outer membranes to each other, and that also connects the vesicle interior to the cytoplasm ${ }^{87}$, indicating possible genesis by invagination, continuing connection with the cytoplasm, or both.

Interconversion of membrane rearrangements. Further evidence linking seemingly distinct membrane rearrangements in RNA replication is that altering the relative levels and interactions of BMV replication factors 1a and $2 \mathrm{a}^{\mathrm{pol}}$ shifts the associated membrane rearrangements between two dramatically distinct forms ${ }^{84}$. Expressing 1a plus low levels of $2 \mathrm{a}^{\mathrm{pol}}\left(1 \mathrm{a} / 2 \mathrm{a}^{\mathrm{pol}} \approx 20\right)$ induces spherular replication complexes matching those of natural bromovirus $^{24,25}$ and alphavirus ${ }^{21}$ infections (FIG. 3c). By contrast, expressing 1a plus higher levels of $2 \mathrm{a}^{\mathrm{pol}}$ induces stacks of appressed double membranes that support RNA replication to levels as high as spherules ${ }^{84}$ (FIG. 3d). The spaces between these double membrane layers parallel spherule interiors in being 50-60 nm wide, containing $1 \mathrm{a}$ and $2 \mathrm{a}^{\mathrm{pol}}$, and being directly connected to the cytoplasm. Therefore, BMV-induced spherules and double membrane layers seem to be functionally and topologically equivalent forms that are built from the same protein-protein and protein-membrane interactions, but in altered proportions.

Similar stacked, double-membrane ER layers and other ordered ER membrane arrays are induced by overexpression of membrane-associated picornavirus replication factors $2 \mathrm{~B}$ and $2 \mathrm{BC}$ (REFS 68,88). Moreover, the double-membrane vesicles associated with picornavirus RNA replication, the spherule-bearing mitochondrial membranes associated with nodavirus RNA replication and the spherule-bearing chloroplast membranes associated with tymovirus RNA replication all cluster by interaction of surface membranes bearing viral replication factors $^{22,23,63,89}$. Therefore, a continuum of vesicle-forming and planar membrane interactions seems to be a normal part of RNA replication by many (+)RNA viruses.

\section{(+)RNA virus and dsRNA virus parallels}

Many of the above parallels between (+)RNA viruses and retroviruses extend to dsRNA viruses, which also sequester genomic RNA templates, viral polymerase and, often, RNA-capping functions in a protein shell for genome replication ${ }^{90,91}$ (FIG. 4C). Possible connections between certain $(+)$ RNA and dsRNA viruses were recognized previously, based on conservation of polymerase $^{5,92}$ and, in one case, on additional replication-factor sequences $^{93}$.

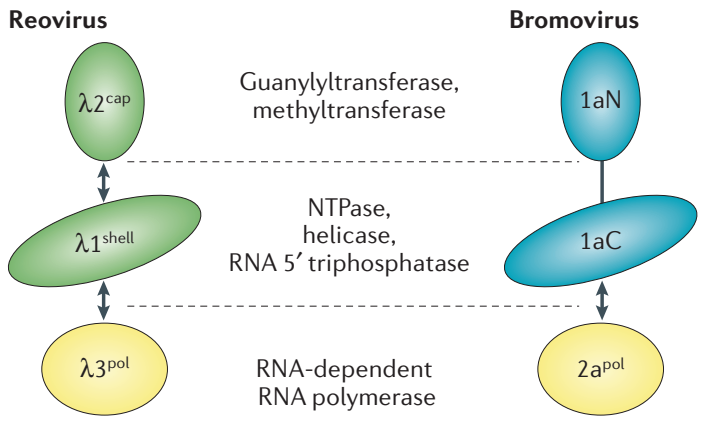

Figure 5 | Structure-function parallels between reovirus and bromovirus RNA-replication factors. The schematics illustrate similarities between interaction and function of reovirus core shell-forming protein $\lambda 1$, RNAcapping protein $\lambda 2$ and RNA-dependent polymerase $\lambda 3$, and the interactions and functions of the brome mosaic virus (BMV) 1a C-proximal NTPase/helicase domain (1aC), 1 a N-proximal RNA-capping domain (1aN) and $2 a^{\text {pol }}$ RNAdependent RNA polymerase. The reovirus $\lambda 1-\lambda 2-\lambda 3$ interactions shown in the schematic occur at each of the twelve 5 -fold axes of the reovirus core.

Similarities with Reoviridae cores. BMV RNA-replication factors and replication complexes share several similarities with the icosahedrally symmetric replicative cores of the dsRNA-virus family Reoviridae (FIG. 4). Reoviridae virions consist of one or more outer-protein shells that are shed during cell entry, surrounding an RNA-containing core that synthesizes RNA in vivo and in vitro ${ }^{90}$. For the Orthoreovirus genus of the Reoviridae, the transcriptionally active, dsRNA-containing core is bound by an $\sim 60$-nm icosahedral shell made from 60 dimers of protein $\lambda 1$ (REF. 94). At each of the twelve 5-fold axes of the core, one copy of the $\lambda 3$ polymerase resides inside the shell ${ }^{95}$, whereas on the shell exterior, a pentamer turret of the $\lambda 2$ capping proteins surrounds the 5 -fold axis ${ }^{94}$. The $\lambda 3$ polymerase copies the genomic dsRNA templates into new (+)RNA progeny, exporting the nascent RNAs to the cytoplasm through the $\lambda 2$ pentamer turret, which adds $m^{7} \mathrm{G}$ caps to the $5^{\prime}$ ends.

BMV 1a shows many parallels in function and protein-protein interactions with reovirus core proteins $\lambda 1$ and $\lambda 2$, implying potentially similar roles in RNA synthesis (FIG. 5). 1a parallels $\lambda 1$ as the self-interacting, high-copy-number inducer of the viral RNA-replication compartment, yielding the spherular BMV replication complexes. The 50-70-nm intra-membrane diameter of these spherules is similar to the reovirus $\lambda 1$ core-protein shell. The C-terminal 1a NTPase/helicase domain and its alphavirus homologues have NTPase, RNA $5^{\prime}$-triphosphatase and helicase activities ${ }^{96-99}$, matching $\lambda 1$ (REFS 100,101). The 1a NTPase/helicase domain also anchors BMV RNA polymerase $2 \mathrm{a}^{\text {pol }}$ to the replication complex by direct interaction ${ }^{102}$, whereas $\lambda 1$ performs the same role for reovirus RNA polymerase $\lambda 3$ (REF. 95). The resulting twelve $\lambda 3$ polymerases per core are similar to the estimated $10-152 \mathrm{a}^{\text {pol }}$ per BMV RNA-replication complex ${ }^{45}$. Continuing these parallels, $\lambda 1$ and the $1 \mathrm{a}$ NTPase/helicase domain each anchor RNA-capping 
functions to the RNA-synthesis complex in the form of reovirus $\lambda 2$ protein and the BMV 1 a N-terminal domain, respectively. $\lambda 2$ (REFS 103,104) and the 1 a $\mathrm{N}$-terminal domain ${ }^{42-44,105}$ both possess guanylyltransferase and methyltransferase activities that add $\mathrm{m}^{7} \mathrm{G}$ caps to the $5^{\prime}$ ends of the (+)RNA products of their respective RNA-synthesis complexes.

RNA packaging, synthesis and export. Recent results indicate possible parallels between the recruitment of (+)RNA templates to BMV RNA-replication complexes and the packaging of $(+)$ RNAs in dsRNA viruses. For dsRNA bacteriophage $\phi 6$, viral (+)RNAs are translocated into a pre-formed, empty core by a hexameric viral NTPase/helicase, P4 (REFS 106,107). Similarly, recruitment of BMV genomic RNAs from a membrane-bound, nuclease-sensitive state into the nuclease-resistant spherule replication complex, but not formation of the membrane-invaginated spherules themselves, is blocked by single amino-acid substitutions that inhibit the NTPase activity of the 1a NTPase/helicase domain ${ }^{99}$. Also, like $\phi 6$ P4, the 1a-homologous NTPase/helicase domain of protein p126 of tobacco mosaic virus forms hexamers ${ }^{108}$. For the Reoviridae, packaging viral $(+)$ RNAs for replication also involves a viral protein with NTPase, RNA-binding and helix-destabilizing activities - the octameric NSP2 for the Rotavirus genus ${ }^{109,110}$ and, potentially, $\mu 2$ for the Orthoreovirus genus ${ }^{90,110,111}$. Like \$6 P4 (REF. 106) and BMV 1a (REF. 112), $\mu 2$ also seems to be a co-factor for $(+)$ RNA synthesis ${ }^{111}$.

For dsRNA viruses, packaging of $(+)$ RNAs is associated with, or followed by, (-)RNA synthesis, yielding dsRNAs that are protected in cores or corelike precursors ${ }^{90,91}$. Similarly, BMV (-)RNA synthesis depends on 1a-mediated (+)RNA recruitment ${ }^{51,52}$, and the resulting (-)RNA products are exclusively

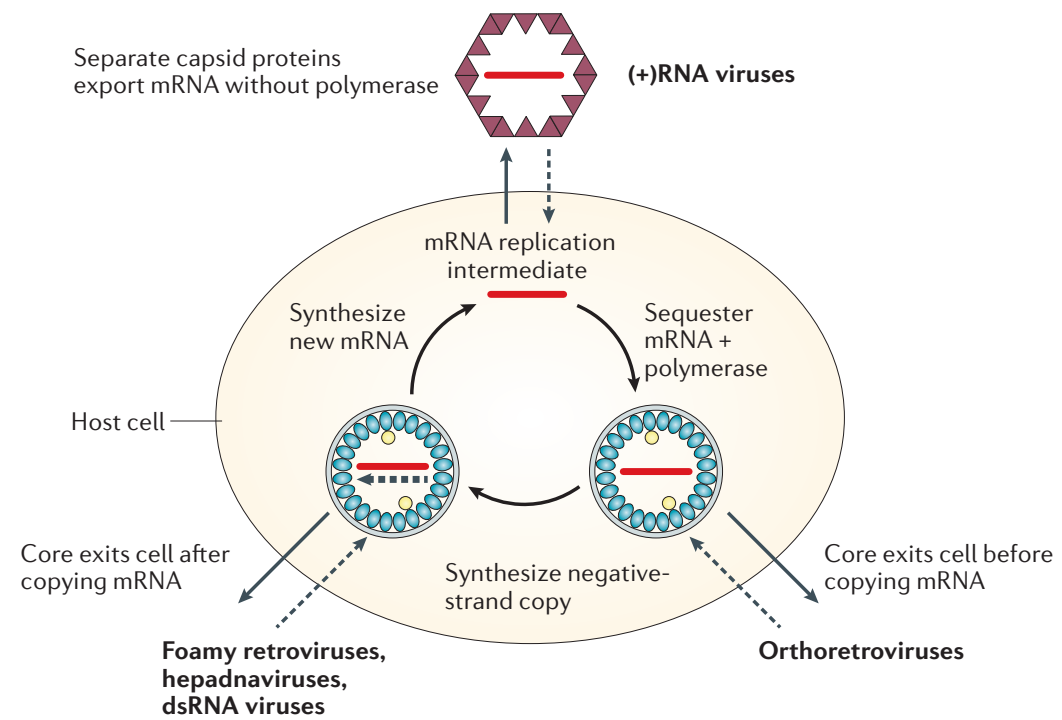

Figure 6 | Parallels and distinctions among the life cycles of reverse-transcribing viruses, (+)RNA viruses and dsRNA viruses. All three classes of virus share a similar replication cycle for their genomic RNA (central cyclical steps) but derive their infectious virions from different intermediates in that cycle (radial arrows). See text for further details. (+)RNA, positive-strand RNA; dsRNA, double-stranded RNA. retained in the nuclease-resistant, membrane-associated RNA-replication compartment ${ }^{45}$. This retention in a virus-induced RNA-replication compartment explains the efficient, repetitive in vivo use of (-)RNAs as templates for (+)RNA synthesis, and the lack of (-)RNA exchange between RNA-replication complexes in the same cell ${ }^{113}$. Compartmentalization of RNA templates also seems to be important in protecting dsRNA-virus genomes and the potentially dsRNA-replication intermediates of $(+)$ RNA viruses ${ }^{25,58}$ from dsRNA-induced host defences, including interferon responses and RNA interference ${ }^{90,91,114-116}$.

A reovirus-like pathway for (+)RNA replication (FIG. $4 \mathrm{~b}, \mathrm{c}$ ) would also explain the common early shutoff of (-)RNA synthesis in BMV and other (+)RNA viruses, while (+)RNA synthesis continues unabated ${ }^{112,117,118}$, and the dependence of (-)RNA synthesis on continuing protein synthesis ${ }^{118}$. In such a model, (-)RNAs might be synthesized primarily during or immediately after replication-complex assembly from newly synthesized proteins, forming dsRNAs that would preferentially or exclusively be templates for (+)RNA synthesis in the resulting stable replication complexes. Replicationcomplex assembly and negative-strand synthesis seem to cease on exhaustion of a limiting host factor, possibly the target membrane for replication-complex formation $^{15,118}$. Pre-formed replication complexes, however, remain active in (+)RNA synthesis ${ }^{112,118}$.

For both the Reoviridae ${ }^{90}$ and the alphavirus-like superfamily ${ }^{119,120},(-)$ RNAs are not capped. By contrast, (+)RNA products are modified with $5^{\prime} \mathrm{m}^{7} \mathrm{G}$ caps and exported to the cytoplasm from both dsRNA virus cores $^{94,95,121}$ and BMV spherules ${ }^{43-45}$. This and the parallels noted above between the capping functions and polymerase interactions of the responsible reovirus proteins and 1a suggest that the transcription/capping/ export complexes at the 5-fold axes of dsRNA-virus cores might provide models for at least some aspects of the corresponding processes at the spherule necks of BMV and other (+)RNA-virus replication complexes.

\section{Possible evolutionary relationships}

The above results show that reverse-transcribing viruses, dsRNA viruses and many, if not all, (+)RNA viruses share central features of genome replication (FIG. 6). Most fundamentally, all replicate their genome through an RNA intermediate that also functions as an mRNA. In all three cases, viral proteins that are translated from these mRNAs capture the mRNA template with its polymerase in a multi-subunit core, sequestering viral RNA from competing processes such as translation and degradation, and sequestering polymerase from competing templates. The polymerase then copies the mRNA into a complementary template from which more mRNA is produced.

The variations on this theme that distinguish the three virus classes primarily relate to possessing an RNA-dependent RNA or DNA polymerase, and to deriving infectious virions from different intermediates in the common replication cycle. Orthoretroviruses, such as HIV, export the replicative core prior to copying 
the mRNA intermediate (FIG. 6, bottom right). By contrast, foamy viruses, hepadnaviruses and dsRNA viruses export the replicative core after copying the mRNA intermediate (FIG. 6, bottom left). For (+)RNA viruses, the virion is separate from the replication complex, and capsid proteins that are not involved in RNA replication package and export the mRNA intermediate before it is sequestered with polymerase (FIG. 6, top). These distinct virion-assembly choices have important consequences, as noted in the introduction, but from some perspectives could be considered temporary extracellular excursions because, as soon as the next cell is infected, each virus re-enters the central, shared replication pathway.

Although no set of shared features can distinguish divergent from convergent evolution, the many parallels summarized here suggest that (+)RNA viruses, dsRNA viruses and reverse-transcribing viruses might have arisen from common ancestors. The transitions required for such evolution can be readily envisioned, and in some cases have precedents. RNA-dependent RNA and DNA polymerases, for example, have related structures ${ }^{122,123}$, and a shift between the two has generally been postulated as the basis for the emergence of DNA-based biology from the RNA world ${ }^{9}$. In keeping with the potential for such transitions, BMV RNA-dependent RNA polymerase can copy DNA templates ${ }^{124}$, and reverse transcriptase can, with single point mutations, incorporate ribonucleotide triphosphates (rNTPs) to produce RNA ${ }^{125}$.

Established and emerging results further indicate that the intracellular RNA-replication complexes of (+)RNA viruses might evolve into infectious extracellular virions, similar to those of dsRNA or reverse-transcribing viruses, by relatively simple modifications. The spherule RNAreplication complexes of alphaviruses, for example, occur on endosomal membranes and, in lesser numbers, at the plasma membrane, where their appearance closely mimics budding virions ${ }^{59}$. Such spherules are released into the medium at low frequency ${ }^{59}$, which might explain the novel infectious particles released from cells replicating alphavirus derivatives with all natural virion proteins deleted and replaced by envelope protein $G$ of vesicular stomatitis virus ${ }^{126}$. As $\mathrm{G}$ protein is readily incorporated into many particles that bud from the plasma membrane and confers the ability to attach to, and fuse membranes with, many cells, incorporation of $\mathrm{G}$ protein into spherule membranes might confer infectivity by allowing released replication complexes or their RNAs to enter new cells.

Once acquired, infectivity might be enhanced and optimized through subsequently selected events. For retroviruses and other enveloped viruses, efficient virion budding requires recruiting functions from the host-cell multivesicular-body pathway ${ }^{57}$. This host machinery can be recruited by incorporating into viral proteins any of a range of short protein-interaction motifs or L domains, which function in a largely positionindependent manner ${ }^{55}$. RNA-recombination events that are suitable to acquire such L domains, favourable envelope-protein genes or other relevant functions from cellular or other viral RNAs are rampant in (+)RNA viruses and retroviruses, representing a major force in virus evolution ${ }^{127-129}$.
Additional pathways for evolutionary transitions between the intracellular RNA-replication complexes of $(+)$ RNA viruses and dsRNA virions have recently been suggested $^{6,130}$. As the replication complexes of $(+)$ RNA viruses are invariably membrane-associated, it is notable that virions of the Rotavirus genus of the dsRNA Reoviridae bud through membranes during assembly and exit from cells ${ }^{131}$. Moreover, rotavirus transmembrane protein nsP4, which mediates virion-core association with ER membranes, is required for correct assembly of the viroplasms in which core assembly and replicative RNA synthesis occur, indicating linkage of these processes with membranes ${ }^{132,133}$. dsRNA bacteriophage $\phi 6$ virions also become membrane-enveloped during exit ${ }^{134}$.

Whereas most views of virus relationships have tended to emphasize the features and classes depicted in FIG. 1, it is intriguing that several alternative, orthogonal virus groupings are defined and mutually distinguished by features that are more strongly conserved across two or more of the classes in FIG. 1. Selected examples include the conservation of an unusual polymerase-sequence rearrangement between $(+)$ RNA tetraviruses and dsRNA birnaviruses $^{5}$, or the use of protein-primed genome replication by the (+)RNA picornaviruses, dsRNA birnaviruses and reverse-transcribing hepadnaviruses ${ }^{3,4,7}$, in contrast to the use of tRNA-like elements by bromoviruses and retroviruses. Such relationships suggest that transitions between the virus classes depicted in FIG. 1 might have evolved on more than one occasion, and that links between viruses within a class might not always be as strong as links between classes.

\section{Implications for virus control}

The emergence of common underlying principles in the central replication processes of $(+)$ RNA viruses, reverse-transcribing viruses and dsRNA viruses suggests that some of these shared features might provide useful targets for broader-spectrum or generalizable approaches for virus control. One approach might be to modulate membrane lipid composition, as recent results show that assembly and function of membraneassociated (+)RNA-virus replication complexes and retrovirus caspids are highly sensitive to the lipid composition of their target membranes, which in at least some cases can be manipulated by small-molecule therapeutics ${ }^{135-138}$. Another general approach might be to interfere with oligomerization or function of oligomerizing replication factors such as retrovirus Gag and BMV 1a by dominant negative mutants ${ }^{43,99}$, inhibition of required chaperones ${ }^{139,140}$, targeted incorporation of destructive ligands or other approaches. Further interventions might be based on interfering with viral RNA interactions that are essential for genome packaging, replication and other steps, using nucleic-acid aptamers or other inhibitors ${ }^{141}$. Other approaches might interfere with the trafficking of viral replication factors and RNAs to their required intracellular sites of assembly ${ }^{142}$. Opportunities for such interference will continue to increase as further aspects of these processes are understood in greater detail. 


\section{Concluding remarks}

An exciting aspect of current virology is that advancing results have not only continued to enrich our understanding of individual viruses, but also to reveal unifying principles that link many aspects of virus infection, replication and host interactions across a surprisingly wide breadth of virus-host systems. The resulting insights display a fundamental order within the vast and sometimes apparently chaotic diversity of known viruses, with important ramifications for virus function and evolution. As the full extent of this tapestry of relations is still emerging, ongoing studies will continue to extend and refine the underlying mechanistic connections. In association with their mechanistic importance, the results should have a growing impact on our abilities to limit the continuing toll and emerging threat of viral diseases, and to develop the beneficial uses of viruses.
1. Butel, J. S. Viral carcinogenesis: revelation of molecular mechanisms and etiology of human disease. Carcinogenesis 21, 405-426 (2000).

2. Talbot, S. J. \& Crawford, D. H. Viruses and tumours an update. Eur. J. Cancer 40, 1998-2005 (2004)

3. Paul, A. V., Rieder, E., Kim, D. W., van Boom, J. H. \& Wimmer, E. Identification of an RNA hairpin in poliovirus RNA that serves as the primary template in the in vitro uridylylation of VPg. J. Virol. 74 10359-10370 (2000)

4. Murray, K. E. \& Barton, D. J. Poliovirus CRE-dependent VPg uridylylation is required for positive-strand RNA synthesis but not for negative-strand RNA synthesis. J. Virol. 77, 4739-4750 (2003). References 3 and 4 reveal and refine parallels in protein-primed genome replication by RNA picornaviruses and reverse-transcribing hepatitis B virus.

5. Gorbalenya, A. E. et al. The palm subdomain-based active site is internally permuted in viral RNAdependent RNA polymerases of an ancient lineage. J. Mol. Biol. 324, 47-62 (2002).

Reveals that an unusual re-ordering of polymerase domains is shared by certain (+)RNA viruses and dsRNA viruses.

6. Coulibaly, F. et al. The birnavirus crystal structure reveals structural relationships among icosahedral viruses. Cell 120, 761-772 (2005).

7. Ahlquist, P. Virus evolution: fitting lifestyles to a T. Curr. Biol. 15, R465-R467 (2005).

8. Weiner, A. M. \& Maizels, N. tRNA-like structures tag the $3^{\prime}$ ends of genomic RNA molecules for replication: implications for the origin of protein synthesis. Proc. Natl Acad. Sci. USA 84, 7383-7387 (1987). Proposes evolutionary relationships among tRNAlike 3' ends of certain (+)RNA-virus genomic RNAs, retroviral tRNA priming and chromosomal telomeres.

9. Maizels, N. \& Weiner, A. M. in The RNA World (ed Gesteland, R. F., Cech, T. R. \& Atkins, J. F.) 79-11 (Cold Spring Harbor Laboratory Press, Cold Spring Harbor, 1999).

10 Miller, W. A., Bujarski, J. J., Dreher, T. W. \& Hall, T. C. Minus-strand initiation by brome mosaic virus replicase within the 3 ' tRNA-like structure of native and modified RNA templates. J. Mol. Biol. 187, 537-546 (1986).

11. Dreher, T. W. \& Hall, T. C. Mutational analysis of the tRNA mimicry of brome mosaic virus RNA. Sequence and structural requirements for aminoacylation and 3'-adenylation. J. Mol. Biol. 201, 41-55 (1988).

12. Dreher, T. W. \& Hall, T. C. Mutational analysis of the sequence and structural requirements in brome mosaic virus RNA for minus strand promoter activity. J. Mol. Biol. 201, 31-40 (1988).

13. Choi, S. K., Hema, M., Gopinath, K., Santos, J. \& Kao, C. Replicase-binding sites on plus- and minusstrand brome mosaic virus RNAs and their roles in RNA replication in plant cells. J. Virol. 78, 13420-13429 (2004).

14. Wang, H. \& Lambowitz, A. M. The Mauriceville plasmid reverse transcriptase can initiate cDNA synthesis de novo and may be related to reverse transcriptase and DNA polymerase progenitor. Cell 75, 1071-1081 (1993).

Identifies a natural intermediate between tRNAprimed retrovirus reverse transcription and de novo RNA synthesis on tRNA-like $3^{\prime}$ ends of some RNA viruses.

15. Restrepo-Hartwig, M. \& Ahlquist, P. Brome mosaic virus helicase- and polymerase-like proteins colocalize on the endoplasmic reticulum at sites of viral RNA synthesis. J. Virol. 70, 8908-8916 (1996).
16. Restrepo-Hartwig, M. \& Ahlquist, P. Brome mosaic virus RNA replication proteins $1 \mathrm{a}$ and 2 a colocalize and $1 \mathrm{a}$ independently localizes on the yeast endoplasmic reticulum. J. Virol. 73, 10303-10309 (1999).

17. Pedersen, K. W., van der Meer, Y., Roos, N. \& Snijder, E. J. Open reading frame 1 -a-encoded subunits of the arterivirus replicase induce endoplasmic reticulum-derived double-membrane vesicles which carry the viral replication complex. J. Virol. 73, 2016-2026 (1999).

18. Suhy, D. A., Giddings, T. H., Jr \& Kirkegaard, K. Remodeling the endoplasmic reticulum by poliovirus infection and by individual viral proteins: an autophagy-like origin for virus-induced vesicles. J. Virol. 74, 8953-8965 (2000).

19. Gosert, R. et al. Identification of the hepatitis $C$ virus RNA replication complex in Huh-7 cells harboring subgenomic replicons. J. Virol. 77, 5487-5492 (2003).

20. Grimley, P. M., Berezesky, I. \& Friedman, R. M Cytoplasmic structures associated with an arbovirus infection: loci of viral ribonucleic acid synthesis. J. Virol. 2, 1326-1338 (1968)

21. Froshauer, S., Kartenbeck, J. \& Helenius, A. Alphavirus RNA replicase is located on the cytoplasmic surface of endosomes and lysosomes. J. Cell Biol. 107, 2075-2086 (1988). References 20 and 21 are classic papers showing association of alphavirus RNA synthesis with modified intracellular membranes.

22. Miller, D. J., Schwartz, M. D. \& Ahlquist, P. Flock house virus RNA replicates on outer mitochondrial membranes in Drosophila cells. J. Virol. 75, 11664-11676 (2001)

23. Prod'homme, D., Le Panse, S., Drugeon, G. \& Jupin, I. Detection and subcellular localization of the turnip yellow mosaic virus $66 \mathrm{~K}$ replication protein in infected cells. Virology 281, 88-101 (2001).

24. Kim, K. S. An ultrastructural study of inclusions and disease in plant cells infected by cowpea chlorotic mottle virus. J. Gen. Virol. 35, 535-543 (1977)

25 Hatta, T. \& Francki, R. I. B. Cytopathic structures associated with tonoplasts of plant cells infected with cucumber mosaic and tomato aspermy viruses. J. Gen Virol. 53, 343-346 (1981)

26. Morikawa, Y. HIV capsid assembly. Curr. HIV Res. 1 , 1-14 (2003).

27. Scarlata, S. \& Carter, C. Role of HIV-1 Gag domains in viral assembly. Biochim. Biophys. Acta 1614, 62-72 (2003)

28. Swanstrom, R \& Wills, J W in Retroviruses (eds Coffin, J. M., Hughes, S. H. \& Varmus, H. E.) 263-334 (Cold Spring Harbor Laboratory Press, Cold Spring Harbor, 1997).

29. Ansari-Lari, M. A. \& Gibbs, R. A. Expression of human immunodeficiency virus type 1 reverse transcriptase in trans during virion release and after infection. $J$. Virol. 70, 3870-3805 (1996)

30. Yuan, B., Fassati, A., Yueh, A. \& Goff, S. P. Characterization of Moloney murine leukemia virus p12 mutants blocked during early events of infection. J. Virol. 76, 10801-10810 (2002)

31. Nermut, M. V. \& Fassati, A. Structural analyses of purified human immunodeficiency virus type intracellular reverse transcription complexes. J. Virol. 77, 8196-8206 (2003).

32. Garfinkel, D. J., Boeke, J. D. \& Fink, G. R. Ty element transposition: reverse transcriptase and virus-like particles. Cell 42, 507-517 (1985).

33. Eichinger, D. J. \& Boeke, J. D. The DNA intermediate in yeast Ty 1 element transposition copurifies with virus-like particles: cell-free Ty1 transposition. Cell 54, 955-966 (1988).
34. Linial, M. L. Foamy viruses are unconventional retroviruses. J. Virol. 73, 1747-1755 (1999).

35. Palmer, K. J. et al. Cryo-electron microscopy structure of yeast Ty retrotransposon virus-like particles. J. Virol. 71, 6863-6868 (1997)

36 Briggs, J. A et al. The stoichiometry of Gag protein in HIV-1. Nature Struct. Mol. Biol. 11, 672-675 (2004).

37. Shehu-Xhilaga, M., Crowe, S. M. \& Mak, J. Maintenance of the Gag/Gag-Pol ratio is important for human immunodeficiency virus type 1 RNA dimerization and viral infectivity. J. Virol. 75 , 1834-1841 (2001)

38. Berkowitz, R., Fisher, J. \& Goff, S. P. RNA packaging. Curr. Top. Microbiol. Immunol. 214, 177-218 (1996)

39. D'Souza, V. \& Summers, M. F. Structural basis for packaging the dimeric genome of Moloney murine leukaemia virus. Nature 431, 586-590 (2004).

40. Ahlquist, P. et al. Sindbis virus proteins nsP 1 and nsP2 contain homology to nonstructural proteins from several RNA plant viruses. J. Virol. 53, 536-542 (1985).

41. van Regenmortel, M. H. V. (ed.) Virus Taxonomy (Academic Press, San Diego, 2000).

42. Ahola, T. \& Ahlquist, P. Putative RNA capping activities encoded by brome mosaic virus: methylation and covalent binding of guanylate by replicase protein $1 \mathrm{a}$. J. Virol. 73, 10061-10069 (1999).

43. Ahola, T., den Boon, J. A. \& Ahlquist, P. Helicase and capping enzyme active site mutations in brome mosaic virus protein 1 a cause defects in template recruitment, negative-strand RNA synthesis, and viral RNA capping. J. Virol. 74, 8803-8811 (2000).

44. Kong, F., Sivakumaran, K. \& Kao, C. The N-terminal half of the brome mosaic virus 1 a protein has RNA capping-associated activities: specificity for GTP and S-adenosylmethionine. Virology 259, 200-210 (1999).

45. Schwartz, M. et al. A positive-strand RNA virus replication complex parallels form and function of retrovirus capsids. Mol. Cell 9, 505-514 (2002). Reveals parallels between the structure, assembly and function of bromovirus RNA-replication complexes and retrovirus virions.

46. Kao, C. C. \& Ahlquist, P. Identification of the domains required for direct interaction of the helicase-like and polymerase-like RNA replication proteins of brome mosaic virus. J. Virol. 66, 7293-7302 (1992)

47. Chen, J. \& Ahlquist, P. Brome mosaic virus polymerase like protein $2 \mathrm{a}$ is directed to the endoplasmic reticulum by helicase-like viral protein 1a. J. Virol. $\mathbf{7 4}$, 4310-4318 (2000)

48. Chen, J., Noueiry, A. \& Ahlquist, P. An alternate pathway for recruiting template RNA to the brome mosaic virus RNA replication complex. J. Virol. 77 2568-2577 (2003).

49. Janda, M. \& Ahlquist, P. Brome mosaic virus RNA replication protein 1a dramatically increases in vivo stability but not translation of viral genomic RNA3. Proc. Natl Acad Sci. USA 95, 2227-2232 (1998).

50. Sullivan, M. \& Ahlquist, P. Cis-acting signals in bromovirus RNA replication and gene expression networking with viral proteins and host factors. Semin. Virol. 8, 221-230 (1997).

51. Chen, J., Noueiry, A. \& Ahlquist, P. Brome mosaic virus protein 1 a recruits viral RNA2 to RNA replication through a 5' proximal RNA2 signal. J. Virol. 75, 3207-3219 (2001)

52. Sullivan, M. \& Ahlquist, P. A brome mosaic virus intergenic RNA3 replication signal functions with viral replication protein 1 a to dramatically stabilize RNA in vivo. J. Virol. 73, 2622-2632 (1999)

53. den Boon, J., Chen, J. \& Ahlquist, P. Identification of sequences in brome mosaic virus replicase protein 1a that mediate association with endoplasmic reticulum membranes. J. Virol. 75, 12370-12381 (2001). 
54. O'Reilly, E. K., Wang, Z., French, R. \& Kao, C. C. Interactions between the structural domains of the RNA replication proteins of plant-infecting RNA viruses. J. Virol. 72, 7160-7169 (1998).

55. Freed, E. O. Viral late domains. J. Virol. 76, 4679-4687 (2002).

56. McMahon, H. T. \& Mills, I. G. COP and clathrin-coated vesicle budding: different pathways, common approaches. Curr. Opin. Cell Biol. 16, 379-391 (2004).

57. Morita, E. \& Sundquist, W. I. Retrovirus budding Annu. Rev. Cell Dev. Biol. 20, 395-425 (2004).

58. Lee, J.-Y., Marshall, J. A. \& Bowden, D. S. Characterization of rubella virus replication complexes using antibodies to double-stranded RNA. Virology 200, 307-312 (1994).

59. Kujala, P. et al. Biogenesis of the Semliki Forest virus RNA replication complex. J. Virol. 75, 3873-3884 (2001).

60. Sethna, P. B. \& Brian, D. A. Coronavirus genomic and subgenomic minus-strand RNAs copartition in membrane-protected replication complexes. J. Virol. 71, 7744-7749 (1997)

61. Miyanari, Y. et al. Hepatitis C virus non-structural proteins in the probable membranous compartment function in viral genome replication. J. Biol. Chem. 278, 50301-50308 (2003)

62. Quinkert, D., Bartenschlager, R. \& Lohmann, V. Quantitative analysis of the hepatitis $C$ virus replication complex. J. Virol. 79, 13594-13605 (2005).

63. Lyle, J. M., Bullitt, E., Bienz, K. \& Kirkegaard, K. Visualization and functional analysis of RNAdependent RNA polymerase lattices. Science 296. 2218-2222 (2002).

Shows that poliovirus RNA polymerase can selfinteract in extended networks consistent with RNA replication on membrane surfaces.

64. Panaviene, Z., Panavas, T. \& Nagy, P. D. Role of an internal and two 3'-terminal RNA elements in assembly of tombusvirus replicase. J. Virol. 79 10608-10618 (2005).

65. Salonen, A. et al. Properly folded nonstructural polyprotein directs the Semliki Forest virus replication complex to the endosomal compartment. J. Virol. 77 1691-1702 (2003).

66. Snijder, E. J., van Tol, H., Roos, N. \& Pedersen, K. W. Non-structural proteins 2 and 3 interact to modify host cell membranes during the formation of the arterivirus replication complex. J. Gen. Virol. 82 985-994 (2001)

67. Egger, D. et al. Expression of hepatitis $\mathrm{C}$ virus proteins induces distinct membrane alterations including a candidate viral replication complex. J. Virol. 76, 5974-5984 (2002).

68. Cho, M. W., Teterina, N., Egger, D., Bienz, K. \& Ehrenfeld, E. Membrane rearrangement and vesicle induction by recombinant poliovirus $2 \mathrm{C}$ and $2 \mathrm{BC}$ in human cells. Virology 202, 129-145 (1994).

69. Teterina, N. L. et al. Requirements for assembly of poliovirus replication complexes and negative-strand RNA synthesis. J. Virol. 75, 3841-3850 (2001).

70. Felsenstein, K. M. \& Goff, S. P. Expression of the Gag-Pol fusion protein of Moloney murine leukemia virus without Gag protein does not induce virion formation or proteolytic processing. J. Virol. 62, 2179-2182 (1988).

71. Karacostas, V., Wolffe, E. J., Nagashima, K., Gonda, M. A. \& Moss, B. Overexpression of the HIV-1 Gag-Pol polyprotein results in intracellular activation of HIV-1 protease and inhibition of assembly and budding of virus-like particles. Virology 193 661-671 (1993)

72. Panavas, T., Hawkins, C. M., Panaviene, Z. \& Nagy, P. D. The role of the p33:p33/p92 interaction domain in RNA replication and intracellular localization of $p 33$ and $\mathrm{p} 92$ proteins of Cucumber necrosis tombusvirus. Virology 338, 81-95 (2005).

73. Ishikawa, M., Meshi, T., Motoyoshi, F., Takamatsu, N. \& Okada, Y. In vitro mutagenesis of the putative replicase genes of tobacco mosaic virus. Nucleic Acids Res. 14, 8291-8305 (1986).

74. Li, G. \& Rice, C. M. Mutagenesis of the in-frame opal termination codon preceding nsP4 of Sindbis virus: studies of translational readthrough and its effect on virus replication. J. Virol. 63, 1326-1337 (1989).

75. Noueiry, A. O., Chen, J. \& Ahlquist, P. A mutant allele of essential, general translation initiation factor DED1 selectively inhibits translation of a viral mRNA. Proc. Natl Acad. Sci. USA 97.

12985-12990 (2000).
76. Ishikawa, M., Diez, J., Restrepo-Hartwig, M. \& Ahlquist, P. Yeast mutations in multiple complementation groups inhibit brome mosaic virus RNA replication and transcription and perturb regulated expression of the viral polymerase-like gene. Proc. Natl Acad. Sci. USA 94, 13810-13815 (1997).

77. Kim, S. H., Palukaitis, P. \& Park, Y. I. Phosphorylation of cucumber mosaic virus RNA polymerase 2a protein inhibits formation of replicase complex. EMBO J. 21 2292-2300 (2002)

78. deGroot, R. J., Rümenapf, T., Kuhn, R. J., Strauss, E. G. $\&$ Strauss, J. H. Sindbis virus RNA polymerase is degraded by the $\mathrm{N}$-end rule pathway. Biochemistry 88, 8967-8971 (1991).

79. Hajimorad, M. R. et al. Nla and Nlb of peanut stripe potyvirus are present in the nucleus of infected cells, but do not form inclusions. Virology 224, 368-379 (1996).

80. Levin, H. L., Weaver, D. C. \& Boeke, J. D. Novel gene expression mechanism in a fission yeast retroelement: Tf1 proteins are derived from a single primary translation product. EMBO J. 12, 4885-4895 (1993).

81. Teysset, L., Dang, V. D., Kim, M. K. \& Levin, H. L. A long terminal repeat-containing retrotransposon of Schizosaccharomyces pombe expresses a Gag-like protein that assembles into virus-like particles which mediate reverse transcription. J. Virol. 77, 5451-5463 (2003)

82. Ganser, B. K., Cheng, A., Sundquist, W. I. \& Yeager, M Three-dimensional structure of the M-MuLV CA protein on a lipid monolayer: a general model for retroviral capsid assembly. EMBO J. 22, 2886-2892 (2003).

83. Westaway, E., Mackenzie, J., Kenney, M., Jones, M. \& Khromykh, A. Ultrastructure of Kunjin virus-infected cells: colocalization of NS1 and NS3 with doublestranded RNA, and of NS2B with NS3, in virusinduced membrane structures. J. Virol. 71 , 6650-6661 (1997)

84. Schwartz, M., Chen, J., Lee, W. M., Janda, M. ¿ Ahlquist, P. Alternate, virus-induced membrane rearrangements support positive-strand RNA virus genome replication. Proc. Natl Acad. Sci. USA 101. 11263-11268 (2004)

Shows that outwardly distinct membrane rearrangements, similar to those associated with RNA replication by different viruses, can be induced by the same viral replication proteins.

85. Aizaki, H., Lee, K. J., Sung, V. M., Ishiko, H. \& Lai, M. M. Characterization of the hepatitis $C$ virus RNA replication complex associated with lipid rafts. Virology 324, 450-461 (2004).

86. Gosert, R., Kanjanahaluethai, A., Egger, D., Bienz, K. \& Baker, S. C. RNA replication of mouse hepatitis virus takes place at double-membrane vesicles. J. Virol. 76, 3697-3708 (2002).

87. Schlegel, A., Giddings, J., T., Ladinsky, M. \& Kirkegaard, K. Cellular origin and ultrastructure of membranes induced during polivirus infection. J. Virol. 70, 6576-6588 (1996)

88. Teterina, N. L., Bienz, K., Egger, D., Gorbalenya, A. E. \& Ehrenfeld, E. Induction of intracellular membrane rearrangements by HAV proteins $2 \mathrm{C}$ and $2 \mathrm{BC}$. Virology 237, 66-77 (1997).

89. Egger, D., Pasamontes, L., Bolten, R., Boyko, V. \& Bienz, K. Reversible dissociation of the poliovirus replication complex: functions and interactions of its components in viral RNA synthesis. J. Virol. 70, 8675-8683 (1996)

90. Nibert, M. L. \& Schiff, L. A. in Fields Virology (eds Knipe, D. M. \& Howley, P. M.) 1679-1728 (Lippincott, Williams \& Wilkins, Philadelphia, 2001).

91. Patton, J. T. \& Spencer, E. Genome replication and packaging of segmented double-stranded RNA viruses. Virology 277, 217-225 (2000)

92. Koonin, E. V., Gorbalenya, A. E. \& Chumakov, K. M. Tentative identification of RNA-dependent RNA polymerases of dsRNA viruses and their relationship to positive strand RNA viral polymerases. FEBS Lett. 252, 42-46 (1989)

93. Koonin, E. V., Choi, G. H., Nuss, D. L., Shapira, R. \& Carrington, J. C. Evidence for common ancestry of a chestnut blight hypovirulence-associated doublestranded RNA and a group of positive-strand RNA plant viruses. Proc. Natl Acad. Sci. USA 88 10647-10651 (1991)

94. Reinisch, K. M., Nibert, M. L. \& Harrison, S. C. Structure of the reovirus core at $3.6 \AA$ resolution. Nature 404, 960-967 (2000).
95. Zhang, X., Walker, S. B., Chipman, P. R., Nibert, M. L. $\&$ Baker, T. S. Reovirus polymerase $\lambda 3$ localized by cryo-electron microscopy of virions at a resolution of 7.6 Å. Nature Struct. Biol. 10, 1011-1018 (2003). References 94 and 95 define the structure of transcriptionally active cores of dsRNA reovirus.

96. Gomez de Cedron, M., Ehsani, N., Mikkola, M. L. Garcia, J. A. \& Kaariainen, L. RNA helicase activity of Semliki Forest virus replicase protein NSP2. FEBS Lett. 448, 19-22 (1999).

97. Vasiljeva, L., Merits, A., Auvinen, P. \& Kaariainen, L. Identification of a novel function of the alphavirus capping apparatus. RNA 5'-triphosphatase activity of Nsp2. J. Biol. Chem. 275, 17281-17287 (2000).

98. Li, Y. I. et al. The helicase-like domain of plant potexvirus replicase participates in formation of RNA 5 ' cap structure by exhibiting RNA 5'-triphosphatase activity. J. Virol. 75, 12114-12120 (2001).

99. Wang, X. et al. Brome mosaic virus 1 a nucleoside triphosphatase/helicase domain plays crucial roles in recruiting RNA replication templates. J. Virol. 79 , 13747-13758 (2005).

100. Bisaillon, M., Bergeron, J. \& Lemay, C. Characterization of the nucleoside triphosphate phosphohydrolase and helicase activities of the reovirus $\lambda 1$ protein. J. Biol. Chem. 272. 18298-18303 (1997).

101. Bisaillon, M. \& Lemay, G. Characterization of the reovirus $\lambda 1$ protein RNA 5'-triphosphatase activity. J. Biol. Chem. 272, 29954-29957 (1997).

102. Kao, C. C., Quadt, R., Hershberger, R. P. \& Ahlquist, P. Brome mosaic virus RNA replication proteins $1 \mathrm{a}$ and $2 \mathrm{a}$ form a complex in vitro. J. Virol. 66, 6322-6329 (1992)

103. Luongo, C. L., Contreras, C. M., Farsetta, D. L. \& Nibert, M. L. Binding site for $S$-adenosyl-L-methionine in a central region of mammalian reovirus $\lambda 2$ protein. Evidence for activities in mRNA cap methylation. J. Biol. Chem. 273, 23773-23780 (1998)

104. Luongo, C. L., Reinisch, K. M., Harrison, S. C. \& Nibert, M. L. Identification of the guanylyltransferase region and active site in reovirus mRNA capping protein $\lambda 2$. J. Biol. Chem. 275, 2804-2810 (2000)

105. Li, Y. I., Chen, Y. J., Hsu, Y. H. \& Meng, M. Characterization of the AdoMet-dependent guanylyltransferase activity that is associated with the $\mathrm{N}$ terminus of bamboo mosaic virus replicase. J. Virol. 75, 782-788 (2001)

106. Pirttimaa, M. J., Paatero, A. O., Frilander, M. J. \& Bamford, D. H. Nonspecific nucleoside triphosphatase P4 of double-stranded RNA bacteriophage $\phi 6$ is required for single-stranded RNA packaging and transcription. J. Virol. 76, 10122-10127 (2002).

107. Kainov, D. E. et al. RNA packaging device of doublestranded RNA bacteriophages, possibly as simple as hexamer of P4 protein. J. Biol. Chem. 278 48084-48091 (2003).

108. Goregaoker, S. P. \& Culver, J. N. Oligomerization and activity of the helicase domain of the tobacco mosaic virus 126 - and 183-kilodalton replicase proteins. J. Virol. 77, 3549-3556 (2003).

109. Jayaram, H., Taraporewala, Z., Patton, J. T. \& Prasad, B. V. Rotavirus protein involved in genome replication and packaging exhibits a HIT-like fold. Nature 417, 311-315 (2002)

110. Taraporewala, Z. F. \& Patton, J. T. Nonstructural proteins involved in genome packaging and replication of rotaviruses and other members of the Reoviridae. Virus Res. 101, 57-66 (2004).

111. Kim, J., Parker, J. S., Murray, K. E. \& Nibert, M. L. Nucleoside and RNA triphosphatase activities of orthoreovirus transcriptase cofactor $\mu 2$. J. Biol. Chem 279, 4394-4403 (2004)

112 Kroner, P. A., Young, B. M. \& Ahlquist, P. Analysis of the role of brome mosaic virus 1 a protein domains in RNA replication, using linker insertion mutagenesis. J. Virol. 64, 6110-6120 (1990).

113. Ishikawa, M., Kroner, P., Ahlquist, P. \& Meshi, T. Biological activities of hybrid RNAs generated by 3 '-end exchanges between tobacco mosaic and brome mosaic viruses. J. Virol. 65, 3451-3459 (1991).

114. Ahlquist, P. RNA-dependent RNA polymerases, viruses, and RNA silencing. Science 296, 1270-1273 (2002).

115. Silvestri, L. S., Taraporewala, Z. F. \& Patton, J. T. Rotavirus replication: plus-sense templates for double stranded RNA synthesis are made in viroplasms. J. Virol. 78, 7763-7774 (2004).

116. Gitlin, L., Stone, J. K. \& Andino, R. Poliovirus escape from RNA interference: short interfering RNA-target recognition and implications for therapeutic approaches. J. Virol. 79, 1027-1035 (2005). 
117. Ishikawa, M., Meshi, T., Ohno, T. \& Okada, Y Specific cessation of minus-strand RNA accumulation at an early stage of tobacco mosaic virus infection. J. Virol. 65, 861-868 (1991).

118. Strauss, J. H. $\&$ Strauss, E. G. The alphaviruses: gene expression, replication, and evolution. Microbiol. Rev. 58, 491-562 (1994)

119. Wengler, G., Wengler, G. \& Gross, H. J. Terminal sequences of Sindbis virus-specific nucleic acids: identity in molecules synthesized in vertebrate and insect cells and characteristic properties of the replicative form RNA. Virology 123, 273-283 (1982).

120. Collmer, C. W. \& Kaper, J. M. Double-stranded RNAs of cucumber mosaic virus and its satellite contain an unpaired terminal guanosine: implications for replication. Virology 145, 249-259 (1985).

121. Diprose, J. M. et al. Translocation portals for the substrates and products of a viral transcription complex: the bluetongue virus core. EMBO J. 20 7229-7239 (2001).

122. Hansen, J., Long, A. \& Schultz, S. Structure of the RNA-dependent RNA polymerase of poliovirus. Structure 5, 1109-1122 (1997).

123. Lesburg, C. A. et al. Crystal structure of the RNAdependent RNA polymerase from hepatitis $C$ virus reveals a fully encircled active site. Nature Struct. Biol. 6, 937-943 (1999).

124. Siegel, R. W., Bellon, L., Beigelman, L. \& Kao, C. C. Use of DNA, RNA, and chimeric templates by a viral RNA-dependent RNA polymerase: evolutionary implications for the transition from the RNA to the DNA world. J. Virol. 73, 6424-6429 (1999). Shows that a (+)RNA-virus RNA-dependent RNA polymerase has substantial activity on DNA templates.

125. Gao, G., Orlova, M., Georgiadis, M. M., Hendrickson, W. A. \& Goff, S. P. Conferring RNA polymerase activity to a DNA polymerase: a single residue in reverse transcriptase controls substrate selection. Proc. Natl Acad. Sci. USA 94, 407-411 (1997).

126. Rolls, M. M., Webster, P., Balba, N. H. \& Rose, J. K Novel infectious particles generated by expression of the vesicular stomatitis virus glycoprotein from a selfreplicating RNA. Cell 79, 497-506 (1994).
127. Lai, M. M. RNA recombination in animal and plant viruses. Microbiol. Rev. 56, 61-79 (1992).

128. Nagy, P. D. \& Simon, A. E. New insights into the mechanisms of RNA recombination. Virology 235 1-9 (1997).

129. Worobey, M. \& Holmes, E. C. Evolutionary aspects of recombination in RNA viruses. J. Gen. Virol. 80 2535-2543 (1999)

130. Ahlquist, P. et al. Viral and host determinants of RNA virus vector replication and expression. Vaccine 23 1784-1787 (2005)

131. Estes, M. K. in Fields Virology (eds Knipe, D. M. \& Howley, P. M.) 1747-1785 (Lippincott, Williams \& Wilkins, Philadelphia, 2001).

132. Lopez, T. et al. Silencing the morphogenesis of rotavirus. J. Virol. 79, 184-192 (2005).

133. Silvestri, L. S., Tortorici, M. A., Vasquez-Del Carpio, R. $\&$ Patton, J. T. Rotavirus glycoprotein NSP4 is a modulator of viral transcription in the infected cell. J. Virol. 79, 15165-15174 (2005). References 132 and 133 reveal links between rotavirus transmembrane protein nsP4 and formation of viroplasms in which dsRNA virion-core assembly occurs.

134. Laurinavicius, S., Kakela, R., Bamford, D. H. \& Somerharju, P. The origin of phospholipids of the enveloped bacteriophage $\phi 6$. Virology 326, 182-190 (2004)

135. Lee, W. M., Ishikawa, M. \& Ahlquist, P. Mutation of host $\Delta 9$ fatty acid desaturase inhibits brome mosaic virus RNA replication between template recognition and RNA synthesis. J. Virol. 75, 2097-2106 (2001).

136. Lee, W. M. \& Ahlquist, P. Membrane synthesis, specific lipid requirements, and localized lipid composition changes associated with a positive-strand RNA virus RNA replication protein. J. Virol. 77, 12819-12828 (2003)

137. Ono, A. \& Freed, E. O. Plasma membrane rafts play a critical role in HIV-1 assembly and release. Proc. Natl Acad. Sci. USA 98, 13925-13930 (2001).

138. Kushner, D. B. et al. Systematic, genome-wide identification of host genes affecting replication of a positive-strand RNA virus. Proc. Natl Acad. Sci. USA 100, 15764-15769 (2003).
139 Hu, J., Toft, D. O \& Seeger, C. Hepadnavirus assembly and reverse transcription require a multi-component chaperone complex which is incorporated into nucleocapsids. EMBO J. 16, 59-68 (1997).

140. Tomita, Y. et al. Mutation of host dnaJ homolog inhibits brome mosaic virus negative-strand RNA synthesis. J. Virol. 77, 2990-2997 (2003).

141. Held, D. M., Kissel, J. D., Patterson, J. T., Nickens, D. G. \& Burke, D. H. HIV-1 inactivation by nucleic acid aptamers. Front. Biosci. 11, 89-112 (2006).

142. Resh, M. D. Intracellular trafficking of HIV-1 Gag: how Gag interacts with cell membranes and makes viral particles. AIDS Rev. 7, 84-91 (2005).

143. Khromykh, A. A., Kondratieva, N., Sgro, J. Y., Palmenberg, A. \& Westaway, E. G. Significance in replication of the terminal nucleotides of the flavivirus genome. J. Virol. 77, 10623-10629 (2003).

144. Yang, H., Makeyev, E. V., Butcher, S. J., Gaidelyte, A. \& Bamford, D. H. Two distinct mechanisms ensure transcriptional polarity in double-stranded RNA bacteriophages. J. Virol. 77, 1195-1203 (2003).

145. Wickner, R. B. Double-stranded RNA viruses of Saccharomyces cerevisiae. Microbiol. Rev. 60, 250-265 (1996).

\section{Acknowledgements}

We thank all members of our laboratory for helpful discussions. This work was supported by the National Institutes of Health

\section{Competing interests statement}

The author declares no competing financial interests.

\section{DATABASES}

The following terms in this article are linked online to: Entrez Genome: http://www.ncbi.nlm.nih.gov/entrez/query. fcgi?db=genome

hepatitis C virus | HIV | poliovirus | RNA1 | RNA2 |RNA3 | tobacco mosaic virus | vesicular stomatitis virus

UniProtKB: http://ca.expasy.org/sprot

1 a $\left|2 \mathrm{a}^{\mathrm{pol}}\right| \lambda 1|\lambda 2| \lambda 3 \mid \mathrm{P} 4$

FURTHER INFORMATION

Paul Ahlquist's homepage: http://mcardle.oncology.wisc. edu/faculty/bio/ahlquist_p.html Access to this links box is available online. 